\title{
Investigated of vitreous and serum Asymmetric Dimethylarginine levels in diabetic retinopathy
}

Atilla Alpay ( $\square$ atillaalpay@hotmail.com )

Bulent Ecevit Universitesi

Özlem Özcan

Bulent Ecevit Universitesi

\section{Sılay Cantürk Uğurbaş}

Zonguldak Bulent Ecevit Universitesi Tip Fakultesi

\section{Suat Hayri Uğurbaş N}

Zonguldak Bulent Ecevit Universitesi Tip Fakultesi

\section{Research article}

Keywords: Asymmetric Dimethyl Arginine, ADMA, Vitreus, Diabetic retinopathy, Nitric oxide

Posted Date: May 24th, 2019

DOl: https://doi.org/10.21203/rs.2.9796/v1

License: (c) (1) This work is licensed under a Creative Commons Attribution 4.0 International License. Read Full License 


\section{Abstract}

Purpose To investigate the intravitreal and blood Asymmetric dimethylarginine (ADMA) level in diabetic retinopathy (DR). Materials and Methods Twenty eyes of 20 patients with DR with the decision of vitrectomy, and 20 eyes of 20 patients without diabetes as a control group were included in the study. During vitrectomy, vitreous and minimum $3 \mathrm{ml}$ peripheral blood samples were taken simultaneously. Serum and vitreous ADMA levels were compared between the two groups. Results The serum ADMA level was higher in the diabetic group compared to the non-diabetic group $(p=0,009)$. However, there was no statistically significant difference between the mean vitreous ADMA levels. There was no correlation between serum and vitreous ADMA levels. Conclusion In patients with diabetic retinopathy, serum ADMA levels increased, but no increase in vitreous ADMA levels was detected.

\section{Introduction}

Diabetic retinopathy (DR) is a common complication of diabetes mellitus (DM), which causes vision loss in people of working age. Over the past 25 years, its frequency has increased markedly throughout the world [1-3]. In many studies, it has been reported that serum nitric oxide (NO) levels increased significantly in patients with DM $[4,5]$. NO is an important pulmonary vasodilator that is synthesized from L-arginine in pulmonary vascular endothelial cells by NO synthetase [6]. NO has positive effects on vascular smooth muscle proliferation, platelet aggregation and vascular superoxide production, as well as anti-atherosclerotic characteristics [6, 7]. Asymmetric Dimethyl Arginine (ADMA) is an active molecule that occurs during the proteolysis of post-translationally methylated arginine in proteins, and is an endogenous inhibitor of all isoforms of NOS. ADMA is mainly excreted through the kidney. It is also metabolized intracellularly through the activity of dimethylarginine dimethylamino hydrolase (DDAH) enzymes. ADMA accumulation was first reported in patients with characterized by endothelial dysfunction including hypertension, hypercholesterolemia, hyperglycemia, renal failure and tobacco exposure [8]. The Serum ADMA level was accepted as a marker of endothelial dysfunction because of its high values in coronary artery disease, end-stage renal failure, stroke, hypertension, and DM [9-11]. In addition to macrovascular complications, there was a strong correlation between ADMA and microvascular complications such as diabetic retinopathy [12]. It has been shown that the Aqueous Humor level of ADMA increased in diabetic patients [13].

The aim of this study was to determine whether the level of vitreous ADMA increases in patients with diabetic retinopathy.

\section{Methods}

Twenty eyes of 20 patients diagnosed with DR and vitrectomy decision given, and as a control group, 20 eyes of 20 patients without diabetes were taken into the scope of the study. A complete ophthalmologic examination was performed on all patients. Patients undergone vitrectomy operations, ones with additional ophthalmological diseases other than cataracts and DR; and others with a systemic disease 
except diabetes and hypertension were not included in the research. A three-port 23-gauge pars plana vitrectomy was performed on all eyes. Vitreous samples were taken using 23-gauge vitrectomy cutter. Infusion fluid were opened after vitreous samples were taken to prevent the samples from mixing with the infusion fluid. Approximately $0.3-0.5 \mathrm{ml}$ of liquid was taken. Simultaneously with surgery, a minimum $3 \mathrm{ml}$ peripheral blood sample was taken. The sample was centrifuged at $4000 \mathrm{rpm}$ for 10 minutes and stored at $-80^{\circ} \mathrm{C}$ in deep freezer.

Samples were taken by the same surgeon. No complication related to vitreous removal has occurred in any of the operations. The results were calculated as $\mu \mathrm{mol} / \mathrm{IL}$ for ADMA. Serum and vitreous ADMA analyses were performed using ELISA (Immuniagnostic Bensheim, Germany) kit.

Statistical evaluation was performed using the SPSS 19.0 program. Normal distributions of numerical variables were examined by Shapiro-Wilks test. Differences between groups in terms of variations in the categorical structure were inspected by Chi-square and Fisher's exact Chi-square tests. When parametric test assumptions are provided for the comparison of two groups in terms of numerical variables, the significance test of the difference between the two means; If not, the Mann-Whitney $U$ test was used. When the parametric test assumptions provided, the linear relationship between two variables was compared with the Pearson correlation coefficient; if not, it was examined by the Spearman's correlation coefficient. The results were evaluated at $95 \%$ confidence interval and $p<0.05$ was considered significant.

\section{Results}

A total of 40 eyes of 40 patients, 20 in Group 1 and 20 in Group 2, were included in the study. The mean age of the patients was $58.80 \pm 11.4$ years in group 1 and $59.55 \pm 13.6$ years in group 2 . There was no significant difference between the groups by means of age averages. Sixty-five percent of the patients in Group 1 were diagnosed as tractional retinal detachment. In group 2, 85\% of patients were diagnosed with vitreous hemorrhage. Preoperative BCVA was similar between groups, whereas postoperative BCVA was significantly higher in Group 2 than Group $1(p=0.021)$. The patient's characteristic and indication of surgery are shown in Table 1 . The mean duration of diabetes in patients in group 1 is $14,95 \pm 5,78$ (2-25) years.

Serum ADMA level was found to be $0.59 \pm 0.10 \mu \mathrm{mol} / \mathrm{L}$ and vitreous ADMA level was $0.25 \pm 0.09 \mu \mathrm{mol} / \mathrm{L}$ in diabetic group. In the nondiabetic group, serum ADMA level was $0.54 \pm 0.08 \mu \mathrm{mol} / \mathrm{L}$, and vitreous ADMA level was $0.26 \pm 0.08 \mu \mathrm{mol} / \mathrm{L}$. The difference between serum ADMA levels of diabetic and non-diabetic group was statistically significant $(p=0.009)$, but there was no significant difference between vitreous ADMA levels $(p=0.059)$. Serum and vitreous ADMA levels were not correlated between the two groups $(r=$ $-0.07, p=0.683$ ). There was no correlation between serum and vitreous ADMA levels in the diabetic and non-diabetic groups. (respectively; $r=-0.13, p=0.590 ; r=0.03, p=0.916$ ) (Table 2). There was no significant relationship between the duration of diabetes and serum ADMA level in Group $1(r=0.19$, 
$\mathrm{p}=0.424)$. As the duration of diabetes increased, vitreous ADMA levels decreased, but the negative correlation between them was not significant $(r=-0.42, p=0.062)$.

\section{Discussion}

In this study, serum and vitreous ADMA levels in patients with diabetic retinopathy were investigated and compared with the control group with the same demographic characteristics. Serum ADMA levels were higher in patients with diabetic retinopathy compared to the control group, but there was no elevation in the vitreous ADMA level. In the literature, there are many studies on plasma ADMA levels in patients with Type 2 diabetes mellitus [11,14-16]. Krzyzanowska et al.[16] measured the level of plasma ADMA and homocysteine in 136 patients with type 2 diabetes. Fifty-five of these patients were being diagnosed some macrovascular disease such as stroke, myocardial infarction, coronary artery disease, and peripheral artery disease. The relationship among with macrovascular disease, ADMA and homocysteine was investigated. ADMA and homocysteine levels were significantly higher in the group diagnosed with macrovascular disease. One year later, Krzyzanowska et al.[17] reported that elevated ADMA levels in patients with type 2 diabetes were a strong indicator of cardiovascular events such as myocardial infarction, cerebrovascular event, and death from all causes. In addition, in terms of diabetic complications, it has been reported that there is a strong relationship between ADMA and microvascular complications such as macrovascular and retinopathy [12, 17-19]. There are also studies showing increased plasma ADMA levels in patients with diabetic retinopathy. Malecki et al.[12] examined the relation between plasma ADMA levels and Type 2 diabetic retinopathy in 182 diabetes Type 2 patients and 52 healthy control groups. They identified that the ADMA levels were the highest in patients with diabetic retinopathy $(0.60 \pm 0.06 \mu \mathrm{mol} / \mathrm{l})$, moderate in diabetic patients without diabetic retinopathy $(0.51 \pm 0.06 \mu \mathrm{mol} / \mathrm{l})$, and the lowest in the control group $(0.45 \pm 0.05 \mu \mathrm{mol} / \mathrm{l})$. In our study, mean serum ADMA level was found $0.59 \pm 0.10 \mu \mathrm{mol} / \mathrm{L}$ in diabetic patient group and $0.54 \pm 0.08 \mu \mathrm{mol} / \mathrm{L}$ in control group. Serum ADMA levels were similar to those found by Malecki et al.[12] In our study too, there was statistically significant difference in serum ADMA levels between the patient group and the control group.

In the literature, no study has been found about vitreous ADMA levels in patients with Type 2 diabetes. Sugai et al.[13] investigated ADMA levels in serum and aqueous humor in 17 diabetic and 21 nondiabetic patients and reported that ADMA levels were higher in diabetic patients, especially in patients with advanced diabetic retinopathy, in both serum and aqueous humor. Serum ADMA levels were $0.67 \pm 0.26$ $\mu \mathrm{mol} / \mathrm{L}$ in the advanced diabetic retinopathy group and $0.53 \pm 0.08 \mu \mathrm{mol} / \mathrm{L}$ in the nondiabetic group. ADMA levels in aqueous humor were $0.55 \pm 0.20 \mu \mathrm{mol} / \mathrm{L}$ in the diabetic patient group and $0.32 \pm 0.16$ $\mu \mathrm{mol} / \mathrm{L}$ in the nondiabetic group. However, there was no relationship between serum and aqueous humor ADMA levels in both groups. Du et al.[20] reported that ADMA levels increased in the aqueous humor of diabetic rats and ADMA contributes to the neovascularization of retina in diabetes mellitus. In our study, vitreous ADMA levels in group 1 and group 2 were $0.25 \pm 0.09 \mu \mathrm{mol} / \mathrm{L}$ and $0.26 \pm 0.08 \mu \mathrm{mol} / \mathrm{L}$, respectively. There was no increase in the vitreous ADMA level as in the aqueous humor. The aqueous humor is continuously in circulation and renewed. It is estimated that the aqueous humor completes this cycle in about 2 hours [21]. But the vitreous gel is not renewed. It has also been reported that the glucose 
concentration of the aqueous humor and the serum are almost the same [22]. When glucose concentrations of vitreous and serum were compared, vitreous glucose concentration was found to be lower than serum glucose concentration [23]. Increased plasma levels of glucose, are associated with decreased levels of DDAH that plays a role in the metabolism of ADMA [24]. Due to hyperglycemia in the aqueous humor, ADMA production is stimulated in the anterior chamber. Because the same hyperglycemia is not in the vitreous gel, ADMA production in the vitreous is not the same. Therefore, the concentration of ADMA in the vitreous may not be related to the serum level.

In our study, a decrease in vitreous ADMA level was observed in diabetic group as the duration of diabetes increased. Ersoy et al.[25] found a decrease in serum ADMA levels as the duration of diabetes increased in 83 disease groups. In our study, the same finding was found for the vitreous ADMA level. But

there was no significant correlation between serum ADMA level and the duration of diabetes. This may be due to a small number of patients in our diabetic group. Marcovecchio et al.[26] also found a decrease in serum ADMA level with an increase in the duration of diabetes. The authors could not give a complete explanation to this inverse relationship and they hypothesized that chronic hyperglycemia could lead to damage that would adversely affect ADMA production.

\section{Conclusions}

In this study, although the serum ADMA level was higher in the diabetic patient group. At the vitreous ADMA level of the diabetic patient group, the same increase was not observed. We did not find a relationship between vitreous and serum ADMA levels in diabetic retinopathy. $A$ second finding is that the level of vitreous ADMA in diabetic patients decreases as the duration of diabetes increases. Since the present findings are derived from a small number of patients, in vivo and in vitro studies with groups with a greater number of patients are needed to fully demonstrate the role of ADMA in diabetic retinopathy.

\section{Abbreviations}

ADMA: Asymmetric dimethylarginine DR: Diabetic retinopathy DM: Diabetes mellitus NO: Nitric oxide DDAH: Dimethylarginine dimethylamino hydrolase

\section{Declarations}

\section{Acknowledgements}

Not applicable.

\section{Funding}

Not applicable.

\section{Availability of data and materials}


The datasets used during the current study available from the corresponding author on reasonable request.

\section{Authors' contributions}

The authors' contributions were as follows; $\mathrm{AA}$ and 00 , manuscript writing, conducting study and data collection; AA; designed and supervised the study; 00 , data collection and analysis. All authors read and approved the final manuscript.

\section{Ethics approval and consent to participate}

This study followed the tenets of the Declaration of Helsinki and was approved by the Zonguldak Bülent Ecevit University Clinical Research Ethics Committee. Informed written consent was obtained from all patients before the study.

\section{Consent for publication}

Not applicable.

\section{Competing interests}

The authors declare that they have no competing interest.

\section{Publisher's Note}

Springer Nature remains neutral with regard to jurisdictional claims in published maps and institutional affiliations.

\section{Open Access}

This article is distributed under the terms of the Creative Commons Attribution 4.0 International License (http://creativecommons.org/licenses/by/4.0/), which permits unrestricted use, distribution, and reproduction in any medium, provided you give appropriate credit to the original author(s) and the source, provide a link to the Creative Commons license, and indicate if changes were made. The Creative Commons Public Domain Dedication waiver (http://creativecommons.org/publicdomain/zero/1.0/) applies to the data made available in this article, unless otherwise stated.

Declaration of interest: All of the authors report no conflicts of interest

Financial support: This study was not supported any sponsor.

\section{References}


1. Du JH, Li X, Li R, Xu L, Ma RR, Liu SF, Zhang Z, Sun HZ. Elevation of serum apelin-13 associated with proliferative diabetic retinopathy in type 2 diabetic patients. Int J Ophthalmol. 2014;7(6):968-973.

2. Liu L, Wu X, Liu L, Geng J, Yuan Z, Shan Z, Chen L. Prevalence of diabetic retinopathy in mainland China: a meta-analysis. PLoS One. 2012;7(9):e45264.

3. Wu J, Geng J, Liu L, Teng W, Liu L, Chen L. The Relationship between Estimated Glomerular Filtration Rate and Diabetic Retinopathy. J Ophthalmol. 2015;2015:326209.

4. Assmann TS, Brondani LA, Boucas AP, Rheinheimer J, de Souza BM, Canani LH, Bauer AC, Crispim D. Nitric oxide levels in patients with diabetes mellitus: A systematic review and meta-analysis. Nitric Oxide. 2016;61:1-9.

5. Suwanpradid J, Rojas M, Behzadian MA, Caldwell RW, Caldwell RB. Arginase 2 deficiency prevents oxidative stress and limits hyperoxia-induced retinal vascular degeneration. PLoS One. 2014;9(11):e110604.

6. Klinger JR, Kadowitz PJ. The Nitric Oxide Pathway in Pulmonary Vascular Disease. Am J Cardiol. 2017;120(8S):S71-S79.

7. Yin YL, Zhu ML, Wan J, Zhang C, Pan GP, Lu JX, Ping S, Chen Y, Zhao FR, Yu HY et al. Traditional Chinese medicine xin-mai-jia recouples endothelial nitric oxide synthase to prevent atherosclerosis in vivo. Sci Rep. 2017;7:43508.

8. Franceschelli S, Ferrone A, Pesce M, Riccioni G, Speranza L. Biological functional relevance of asymmetric dimethylarginine (ADMA) in cardiovascular disease. Int J Mol Sci. 2013;14(12):2441224421.

9. Heunisch F, Chaykovska L, von Einem G, Alter M, Dschietzig T, Kretschmer A, Kellner KH, Hocher B. ADMA predicts major adverse renal events in patients with mild renal impairment and/or diabetes mellitus undergoing coronary angiography. Medicine (Baltimore). 2017;96(6):e6065.

10. Lluch P, Segarra G, Medina P. Asymmetric dimethylarginine as a mediator of vascular dysfunction in cirrhosis. World J Gastroenterol. 2015;21(32):9466-9475.

11. Celik M, Cerrah S, Arabul M, Akalin A. Relation of asymmetric dimethylarginine levels to macrovascular disease and inflammation markers in type 2 diabetic patients. J Diabetes Res. 2014;2014:139215.

12. Malecki MT, Undas A, Cyganek K, Mirkiewicz-Sieradzka B, Wolkow P, Osmenda G, Walus-Miarka M, Guzik TJ, Sieradzki J. Plasma asymmetric dimethylarginine (ADMA) is associated with retinopathy in type 2 diabetes. Diabetes Care. 2007;30(11):2899-2901.

13. Sugai M, Ohta A, Ogata Y, Nakanishi M, Ueno S, Kawata T, Saito N, Tanaka Y. Asymmetric dimethylarginine (ADMA) in the aqueous humor of diabetic patients. Endocr J. 2007;54(2):303-309.

14. Jayachandran I, Sundararajan S, Paramasivam P, Venkatesan B, Subramanian SC, Balasubramanyam M, Mohan V, Manickam N. Association of circulatory asymmetric dimethylarginine (ADMA) with diabetic nephropathy in Asian Indians and its causative role in renal cell injury. Clin Biochem. 2017;50(15):835-842. 
15. Hosseinzadeh-Attar M, Kolahdouz Mohammadi R, Eshraghian M, Nakhjavani M, Khorrami E, Ebadi M, Esteghamati A. Reduction in asymmetric dimethylarginine plasma levels by coenzyme Q10 supplementation in patients with type 2 diabetes mellitus. Minerva Endocrinol. 2015;40(4):259-266.

16. Krzyzanowska K, Mittermayer F, Krugluger W, Schnack C, Hofer M, Wolzt M, Schernthaner G. Asymmetric dimethylarginine is associated with macrovascular disease and total homocysteine in patients with type 2 diabetes. Atherosclerosis. 2006;189(1):236-240.

17. Krzyzanowska K, Mittermayer F, Wolzt M, Schernthaner G. Asymmetric dimethylarginine predicts cardiovascular events in patients with type 2 diabetes. Diabetes Care. 2007;30(7):1834-1839.

18. Du MR, Ju GX, Li NS, Jiang JL. Role of Asymmetrical Dimethylarginine in Diabetic Microvascular Complications. J Cardiovasc Pharmacol. 2016;68(4):322-326.

19. Ganz T, Wainstein J, Gilad S, Limor R, Boaz M, Stern N. Serum asymmetric dimethylarginine and arginine levels predict microvascular and macrovascular complications in type 2 diabetes mellitus. Diabetes Metab Res Rev. 2017;33(2).

20. Du MR, Yan L, Li NS, Wang YJ, Zhou T, Jiang JL. Asymmetric dimethylarginine contributes to retinal neovascularization of diabetic retinopathy through EphrinB2 pathway. Vascul Pharmacol. 2018;108:46-56.

21. Brubaker RF. Flow of aqueous humor in humans [The Friedenwald Lecture]. Invest Ophthalmol Vis Sci. 1991;32(13):3145-3166.

22. Takata K, Hirano H, Kasahara M. Transport of glucose across the blood-tissue barriers. Int Rev Cytol. 1997;172:1-53.

23. Lundquist O, Osterlin S. Glucose concentration in the vitreous of nondiabetic and diabetic human eyes. Graefes Arch Clin Exp Ophthalmol. 1994;232(2):71-74.

24. Lin KY, Ito A, Asagami T, Tsao PS, Adimoolam S, Kimoto M, Tsuji H, Reaven GM, Cooke JP. Impaired nitric oxide synthase pathway in diabetes mellitus: role of asymmetric dimethylarginine and dimethylarginine dimethylaminohydrolase. Circulation. 2002;106(8):987-992.

25. Ersoy B, Eroglu N, Cetin M, Onur E, Ozkol M, Coskun S. Asymmetric dimethylarginine levels and diabetes duration: Relationship with measures of subclinical atherosclerosis and cardiac function in children and adolescents with Type 1 diabetes. Diab Vasc Dis Res. 2018;15(3):196-203.

26. Marcovecchio ML, Widmer B, Turner C, Dunger DB, Dalton RN. Asymmetric dimethylarginine in young people with Type 1 diabetes: a paradoxical association with HbA(1c). Diabet Med. 2011;28(6):685691.

\section{Tables}

Table 1. Demographic profiles of patients. 


\begin{tabular}{|c|c|c|c|c|}
\hline & $\begin{array}{c}\text { Patient Group } \\
n=20 \\
\end{array}$ & $\begin{array}{c}\text { Control Group } \\
n=20 \\
\end{array}$ & $p$ \\
\hline \multicolumn{2}{|c|}{ Age (year) } & $58,80 \pm 11,4$ & $59,55 \pm 13,6$ & 0.883 \\
\hline Gender & $\begin{array}{l}\text { Male n (\%) } \\
\text { Female n (\%) }\end{array}$ & $\begin{array}{c}6(30) \\
14(70)\end{array}$ & $\begin{array}{c}14(70) \\
6(30)\end{array}$ & 0.027 \\
\hline \multicolumn{5}{|c|}{ Best corrected visual Acuity (Logmar) } \\
\hline \multicolumn{2}{|c|}{ Preoperative } & $2,04 \pm 0,73$ & $2,07 \pm 1,11$ & $\mathrm{p}=0.942)$ \\
\hline \multicolumn{2}{|c|}{ Postoperative } & $0,96 \pm 0,55$ & $1,67 \pm 1,02$ & $\mathrm{p}=0.021$ \\
\hline \multicolumn{2}{|c|}{ Vitreous hemorrhage } & 13 & 3 & \\
\hline \multicolumn{2}{|c|}{ Tractional retinal detachment } & 7 & & \\
\hline \multicolumn{2}{|c|}{ Rhegmatogenous retinal detachment } & & 17 & \\
\hline
\end{tabular}

Table 2. Comparison of serum and vitreous ADAM levels in cases.

\begin{tabular}{|c|c|c|c|c|}
\hline & s ADMA ( $\mu \mathrm{mol} / \mathrm{L})$ & v ADMA ( $(\mu \mathrm{mol} / \mathrm{L})$ & $\mathbf{r}$ & $\mathrm{p}$ \\
\hline Group $1 \mathrm{n}=20$ & $0.59 \pm 0.10$ & $0.25 \pm 0.09$ & -0.13 & 0.590 \\
\hline Group $2 \mathrm{n}=20$ & $0.54 \pm 0.08$ & $0.26 \pm 0.08$ & 0.03 & 0.916 \\
\hline p & 0,009 & 0,059 & & \\
\hline
\end{tabular}

s; serum, v; vitreous 